\title{
Scar Epidemiology and Consequences
}

M. El Kinani and F. Duteille

\section{Contents}

6.1 Introduction and Background - 46

6.2 Reminder of the Spectrum of Scars - 46

6.2.1 Contractures - 46

6.2.2 Extended Scar -46

6.2.3 Atrophic Scar - 46

6.2.4 Hypertrophic Scar - 46

6.2.5 Keloid Scar - 46

6.3 Hypertrophic Scars - 46

6.4 Basic Epidemiology - 46

6.4.1 Risk Factors -47

6.5 Keloid Scars - 47

6.5.1 Basic Epidemiology - 47

6.5.2 Risk Factors - 47

6.6 Specific Situation: The Burnt Patient Healing - 47

6.6.1 Scarred Hypertrophy in Burned Patients: Epidemiology - 48

6.6.2 Retracted Scars -48

6.7 Impact of Scars -48

6.8 Conclusion -48

References -48 


\subsection{Introduction and Background}

Cutaneous scarring is a dynamic process following a physical alteration of the cutaneous barrier. It is a slow process, taking place in three phases: debridement, granulation and epidermization, each of these phases bringing into play different cellular mediators. Then comes the maturation phase of the scar, which reaches its final appearance usually after two years of evolution.

It is important to distinguish between defective scars, which may result out of poor surgical technique, issuing to a dermal separation, keeping the epidermal layer in continuity. These scars are stable over time and do not belong to the same category than pathological scars, which are true evolutionary abnormalities of cutaneous scarring, linked to abnormal cell proliferation of myofibroblasts, with different scenarios depending on the degree of anarchy of the collagenic bundles.

\subsection{Reminder of the Spectrum of Scars}

\subsubsection{Contractures}

Located generally opposite the joints or when a wound is perpendicular to the lines of Langer, they can alter considerably the function according to their importance and their localization. They are particularly common in burned patients or after a thin or semi-thick skin graft.

\subsubsection{Extended Scar}

They are mainly observed from the first postoperative weeks. Most often pale, asymptomatic, they pose mostly aesthetic problems without functional discomfort. Stretch marks (often abdominal) are a type of enlarged scar and a consequence of a rupture of the dermis, without epidermal alteration. The absence of elevation or thickening differentiates them from hypertrophic scars.

\subsubsection{Atrophic Scar}

The plan of these scars lies under the plan of healthy peripheral skin. They are usually small. Frequent on the face, they are mostly consequences of acne or chicken pox.

\subsubsection{Hypertrophic Scar}

They are characterized clinically by an elevation of the plane of the scar which is thickened, inflammatory, but which remains limited to the cicatricial banks. They never invade the healthy peripheral skin. They are also distinguished from keloid scars by their spontaneous regression within two years of the onset of the wound. They are often itchy and even painful.

\subsubsection{Keloid Scar}

Unlike hypertrophic scars, keloid scars extend beyond the margins and also affect healthy skin around the scar. Functional symptoms (itching and pain) are very common and hinder quality of life. They have no tendency to regress. After excision, the rate of recurrence is major, making the management of these scars, which must be multimodal, complex.

Pathological (hypertrophic or keloid) healing is a complex process, resulting from many factors. During normal healing, the myofibroblasts participating in the cutaneous contraction enter apoptosis. A lack of apoptosis of these myofibroblasts, and consequently their excessive accumulation, explains the occurrence of raised and inflammatory scars [1]. Another factor contributing to the pathogenesis of these scars is an accumulation of immature collagen [2].

\subsection{Hypertrophic Scars}

Hypertrophic scars are the result of excessive proliferation of myofibroblasts and increased deposition of collagen within the scar $[1,2]$. The scar then exceeds to the surface of the healthy peripheral skin, can be inflammatory and itchy, and even painful. They differ from keloid scars due to their tendency to regress within two years and because they never exceed the scarred margins $[3,4,5]$. However, diagnostic errors are still common in practice.

\subsection{Basic Epidemiology}

The frequent confusion between hypertrophic scars and keloids (despite the above definitions) means that there is little data on their epidemiology. The studies found are often of low level of evidence, centered on a given geographic population. Mahdavian Belavary et al [5] studied the rate of hypertrophic scars after breast reduction or median sternotomy. At three months, $60 \%$ of patients developed hypertrophic scars. At one year, there was persistent hypertrophy in $32 \%$ of patients included. These figures are consistent with previous studies, found between $38 \%$ and $68 \%$ postoperative hypertrophic scars [6]. An analysis of data over time would be interesting, in order to evaluate the average duration of evolution of these scars. No sex ratio was found in the literature, as men and women were similarly affected by the occurrence of hypertrophic scars. 


\subsubsection{Risk Factors}

Many risk factors for the occurrence of scarring hypertrophy are admitted. There are many studies in the literature but many are of a low level of proof (levels IV-V). Butzelaar et al. [7] found as major risk factors the age, the existence of allergic terrain, the existence of bacterial colonization (with or without infection) within the wound, and cutaneous tension. Most of the hypertrophic scars are found between the ages of 11 and 30 years. This can be explained by the presence of sagging skin with age and a decrease in the inflammatory response [8]. It is often accepted that a dark phototype (African skin) is a risk factor for hypertrophic scars. Nevertheless, in the literature, the studies are of a low level of proof and the opinion of the authors is partaged, not allowing to bring a valid and reliable conclusion to this idea. Unlike keloid scars, there does not appear to be a genetic cause for the occurrence of hypertrophic scars [9]. Butzelaar et al [7] found a protective trend of smoking for the development of hypertrophic scars. Cancer chemotherapy also seems to be a protective factor; however, there are many confounding factors to consider in the studies in question (role of cancer itself, possible undernutrition).

\subsection{Keloid Scars}

The keloid scar is an abnormality of cutaneous healing specific to humans. The main problems, apart from their unattractive and annoying appearance, are their nonimprovement in the time and frequency of recurrence despite the medical and surgical treatments undertaken. They can even be aggravated by surgical resection if it is not strictly intra-lesional.

\subsubsection{Basic Epidemiology}

Again, few studies have investigated the prevalence or incidence of keloid scars. Yet each year, it is estimated that about 100 million scars are developed, and among them 11 million would become keloids [10].

In the literature, the prevalence varies widely according to the population studied $[3,11]$.The estimations are as follows:

- 4.5 to $16 \%$ in black and Hispanic populations of American origin

- $16 \%$ in Zaire

- only $0.09 \%$ in England

They are responsible for pruritus or pain in $20-40 \%$ of cases [3].

\subsubsection{Risk Factors}

Keloid scars may be found on all localizations, but are more frequent in some areas [11, 12]:

- Ear lobe

- Pre-stern and deltoid region

- Under umbilical area (pubic area)

These are areas where skin tension is important, thus joining the frequent locations of hypertrophic scars. By definition, they do not touch the mucous membranes.

They can be observed at any age but peak frequency is between 10 and 30 years $[13,18]$. Some authors explain this by the role of cutaneous tension which is more important in young subjects [3]. There also appears to be a hormonal factor, keloid scars being more frequent in the pubertal period [3]. The hormonal role is still discussed: if they are actually more common in pubertal period, keloids that appear at these ages also have a tendency to hyperpigmentation. During pregnancy, some authors have observed a more frequent appearance or enlargement of keloid scars [14].

It is also accepted that subjects with a dark phototype are more frequently affected, although we may experience keloid scars in all phototypes $[15,16]$.

The hypothesis of a genetic predisposition is beginning to be well anchored. It is estimated that 5 to $10 \%$ of cases have family keloids [17]. Marneros et al. [18] found that transmission is autosomal-dominant mode, the clinical penetrance is incomplete, and the expression is highly variable. There appears to be susceptibility to the development of keloids in Japanese and African-American families in relation to chromosomes 2 and 7 [19].

There are cases of spontaneous keloids in the literature, but these would ultimately be due to undetected microtrauma [20]

\subsection{Specific Situation: The Burnt Patient Healing}

Hypertrophic scarring after a burn (whether it has healed spontaneously or required skin grafting) is a common problem in clinical practice. In addition to being dysgraculous, these scars are generally itchy and even painful and can significantly alter function and quality of life, especially if they are responsible for skin retraction. Since this type of healing is quite specific to the burned patient, we chose to treat it in a separate chapter. 


\subsubsection{Scarred Hypertrophy in Burned Patients: Epidemiology}

The data of the literature are very variable on this subject. In the majority of cases, the studies are small, and few distinctions are made between the different populations (adults vs. children, light phototype vs. dark phototype, spontaneously scarred burn vs. transplanted).

Deitch et al [21] found a prevalence of $15 \%$ (white patients) to $30 \%$ (black patients) in burn patients who healed spontaneously.

Mc Donald and Deitch [22] analyzed the prevalence of scar hypertrophy in patients treated with thin skin grafts. Of the children included, $75 \%$ had cicatricial hypertrophy. In adults, the prevalence was $50 \%$ in patients with black skin, compared to $7 \%$ in patients with fair skin.

Spurr and Shakespeare [23] followed 82 children and found $65 \%$ hypertrophic scars. Bombaro et al. [24] reported an average of $67 \%$ cicatricial hypertrophy (up to $100 \%$ in children with non-white skin). Finally, Delavary et al. [25] found a rate of $60 \%$ hypertrophic scars in burn patients, mainly in the first three months after the onset of the burn. According to them, young and non-smoking subjects are more likely to develop hypertrophic scars. In each of these studies, the number of patients remains low and the population monocentric. Further and larger studies would be needed to better identify populations at risk. The risk factors identified to date are young age, location of the upper limbs or neck, dark phototype, repetition of surgical procedures, initial severity of burn, and time to heal [25]. Lawrence et al [26] also find these risk factors in the literature, in addition to the female sex and skin grafts that required expansion (mesh-graft). Their review of the literature found a prevalence of hypertrophic scars ranging between 32 and $72 \%$.

\subsubsection{Retracted Scars}

Retraction or contraction of the skin following a burn results from an excessive, hypertrophic scarring, of which we have just spoken. Functional consequences can be major and threaten the socio-professional future of patients. They are frequent and particularly disabling in the articular areas. The prevalence is very variable according to the studies, one finds on average between 38 and $54 \%$ of contraction in the years following the occurrence of the burn [27]. According to the authors, these would be more common in severely burned patients, children, women, and upper limb. Gangemi et al. [28] analyzed 703 burned patients and found on average $77 \%$ of pathological scars ( $44 \%$ hypertrophy, $5 \%$ contractures, $28 \%$ combining both). They also found as risk factors the female sex, the young age, localization of the burning of the upper limb or the neck, the repetition of the surgical procedures, and the expansion of the skin grafts when these are realized.

\subsection{Impact of Scars}

Although many studies concern the epidemiology and management of scars, very few have been interested in the consequences of these scars. However, it is estimated that more than one in two patients are not satisfied with the appearance of their scars, $20 \%$ of patients suffer from anxiety, and more than $50 \%$ feel that their privacy is affected by the presence of their scars [29].

\subsection{Conclusion}

Few studies have really focused on the epidemiology of scars and their consequences. When studies are conducted, they often concentrate around a given geographic population and report only a small number of patients. There are probably many lost sight, since many patients live surely with their scars (hypertrophic, keloids) without consulting. Larger scale studies should be carried out to determine the frequency of occurrence of these scarring abnormalities, in order to better identify them and, consequently, to better treat them.

\section{T Take Home Message \\ The epidemiology of pathologic scars is diverse. Sixty percent of scars located on the thorax may become hypertrophic, and a patient from Zaire has $100 \%$ more risks to develop a keloid than a patient native from England. Burns may issue up to $77 \%$ of pathologic scars, combining hypertrophic, retractile, and keloid scars. The role of hormonal status, nutrition, and many other factors has been suspected in keloids.}

\section{References}

1. Sarrazy V, Billet F, Micallef L, Coulomb B, Desmoulière A. Mechanisms of pathological scarring: role of myofibroblasts and current developments. Wound Rep Reg. 2011;19:S10-5.

2. Ehrlich HP, Desmouliere A, Diegelmann RF, et al. Morphological and immunochemical differences between keloid and hypertrophic scar. Ann J Pathol. 1994;145:105.

3. Rockwell WB, Cohen IK, Ehrlich HP. Keloids and hypertrophic scars. A comprehensive review. Plast Reconstr Surg. 1989;84:82737; Burd A, Huang I. Hypertrophic response and keloid diathe- 
sis: two very different forms of scar. Plast Reconstr Surg. 2005; $116: 150 \mathrm{e}-7 \mathrm{e}$.

4. Atiyeh BS, Costagliola M, Hayek SN. Keloid or hypertrophic scar, the controversy: review of the literature. Ann Plast Surg. 2005;54(6):676-80.d.

5. Mahdavian Delavary B, Van der Veer WM, Ferreira JA, Niessen FB. Formation of hypertrophic scars: evolution and susceptibility. J Plast Surg Hand Surg. 2012;46:95-101.

6. Elliot D, Cory-Pearce R, Rees GM. The behavior of presternal scars in a fair-skinned population. Ann R Coll Surg Engl. 1985;67:238-40.

7. Butzelaar, et al. Currently known risk factors for hypertrophic skin scarring: a review. J Plast Rec Aesth Surg. 2016;69:163-9.

8. Enoch S, Price PE. Cellular, molecular and biochemical differences in the pathophysiology of healing between acute wounds, chronic wounds and wounds in the aged. World Wild Wounds;2004;ISSN 1369-2607.

9. Brown JJ, Bayat A. Genetic susceptibility to raised dermal scarring. Br J Dermatol. 2009;161:8-18.

10. Bayat A, McGrouther DA, Ferguson MW. Skin scarring. BMJ. 2003;326:88-92.

11. Philandrianos C, et al. Keloid scars (part I): Clinical presentation, epidemiology, histology and pathogenesis. Ann Chir Plast Esthet. 2015;1181

12. Crockett DJ. Regional keloid susceptibility. Br J Plast Surg 1964;17:245-53.

13. Bayat A, Arscott G, Ollier WE, McGrouther DA, Ferguson MW. Keloid disease: clinical relevance of single versus multiple site scars. Br J Plast Surg. 2005;58(1):28-37.

14. Moustafa MF, Abdel-Fattah MA, Abdel-Fattah DC. Presumptive evidence of the effect of pregnancy estrogens on keloid growth. Plast Reconstr Surg. 1975;56:450-3.

15. Allah KC, Yeo S, Kossoko H, Assi Dje Bi Dje V, Richard KM. Keloid scar on black skin: myth or reality. Ann Chir Plast Esthet. 2013;58(2):115-22.

16. Niessen FB, Spauwen PH, Schalkwijk J, Kon M. On the nature of hypertrophic scars and keloids: a review. Plast Reconstr Surg. 1999;104(5):1435-58.
17. Martinet L. La cicatrice chéloïde: étude retrospective sur quinze ans. [Thèse 2007]

18. Marneros AG, Norris JEC, Olsen BR, Reichenberger E. Clinical genetics of familial keloids. Arch Dermatol. 2001;131(11): 1429-34.

19. Marneros AG, Norris JEC, Watanabe S, Reichenberger E, Olsen BR. Genome scans provide evidence for keloid susceptibility loci on chromosomes $2 \mathrm{q} 23$ and $7 \mathrm{p} 11$. J Invest Dermatol. 2004; 122:1126.

20. Pitche P. What is true in "spontaneous keloids"? Ann Dermatol Venerol. 2006;133:501.

21. Deitch EA, Wheelahan TM, Rose MO, Clothier J, Cotter J. Hypertrophic burn scars: analysis of variables. J Trauma. 1983;23:895-8.

22. McDonal WS, Deitch EA. Hypertrophic skin grafts in burned patients: a prospective analysis of variables. J Trauma. 1987;27:147-50.

23. Spurr ED, Shakespeare PG. Incidence of hypertrophic scarring in burn-injured children. Burns. 1990;16:179-81.

24. Bombaro KM, Engrav LH, Carrougher GJ, Wiechman SA, Faucher L, Costa BA, et al. What is the prevalence of hypertrophic scarring following burns? Burns. 2003;29(4):299-302.

25. Delavary BM, Van der Veer WM, Ferreira JA, Niessen FB. Formation of hypertrophic scars: evolution and susceptibility. J Plast Surg Hand Surg. 2012;46:95-101.

26. Lawrence JW, Mason ST, Schomer K, Klein MB. Epidemiology and impact of scarring after burn injury: a systematic review of literature. J Burn Care Res. 2012;33:136-46.

27. Oosterwijk, et al. Prevalence of scar contractures after burn: a systematic review. Burns. 2017;43:41-9.

28. Gangemi EN, Gregori D, Berchialla P, et al. Epidemiology and risk factors for pathological scarring after burn wounds. Arch Facial Plast Surg. 2008;10:93-102.

29. Brown BC, McKenna SP, Siddhi K, McGrouther DA, Bayat A. The hidden cost of skin scars : quality of life after skin scarring. J Plast Recon Aesth Surg. 2008;61:1049-58.

Open Access This chapter is licensed under the terms of the Creative Commons Attribution 4.0 International License (http://creativecommons. org/licenses/by/4.0/), which permits use, sharing, adaptation, distribution and reproduction in any medium or format, as long as you give appropriate credit to the original author(s) and the source, provide a link to the Creative Commons license and indicate if changes were made.

The images or other third party material in this chapter are included in the chapter's Creative Commons license, unless indicated otherwise in a credit line to the material. If material is not included in the chapter's Creative Commons license and your intended use is not permitted by statutory regulation or exceeds the permitted use, you will need to obtain permission directly from the copyright holder.

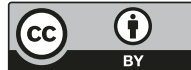

